LAW, ETHICS AND MEDICINE

\title{
Relatives' knowledge of decision making in intensive care
}

\author{
M G Booth, P Doherty, R Fairgrieve, J Kinsella
}

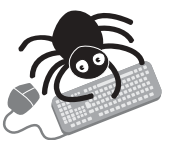

Additional information available on the website

See end of article for authors' affiliations

.....................

Correspondence to: Dr M G Booth, Department of Anaesthesia, Glasgow Royal Infirmary, Castle Street, Glasgow G4 OSF UK; mgb2j@udcf.gla.ac.uk

Received 18 June 2002 In revised form

9 December 2002

Accepted for publication

13 February 2003

Background/Aim: The law on consent has changed in Scotland with the introduction of the Adults with Incapacity (Scotland) Act 2000. This Act introduces the concept of proxy consent in Scotland. Many patients in intensive care are unable to participate in the decision making process because of their illness and its treatment. It is normal practice to provide relatives with information on the patient's condition, treatment, and prognosis as a substitute for discussion directly with the patient. The relatives of intensive care patients appeared to believe that they already had the right to consent on behalf of an incapacitated adult. The authors' aim was to assess the level of knowledge among relatives of intensive care patients of both the old and new law using a structured questionnaire.

Methods: The next of kin of 100 consecutive patients completed a structured questionnaire. Each participant had the questions read to them and their answers recorded. Patients were not involved in the study.

Results: Few $(10 \%)$ were aware of the changes. Most (88\%) thought that they previously could give consent on behalf of an incapacitated adult. Only 13\% have ever discussed the preferences for life sustaining treatment with the patient but $84 \%$ felt that they could accurately represent the patient's wishes.

Conclusions: There appeared to be a lack of public awareness of the impending changes. The effectiveness of the Act at improving the care of the mentally incapacitated adult will depend largely on how successful it is at encouraging communication and decision making in advance of incapacity occurring.

O btaining a patient's consent is a prerequisite before performing any form of intervention or medical treatment. Non-consensual contact is a potential assault. This is true even in the situation where life saving treatment is required immediately before consent can be obtained. Actions performed in an emergency can be justified under the Common Law. In England they can also be sanctioned under the "principle of necessity". ${ }^{2}$

In Scotland, before the introduction of the Adults with Incapacity (Scotland) Act 2000, no other adult could consent on behalf of another adult who lacked capacity. ${ }^{3}$ The exception to this was where a tutor dative had been appointed (a person formally appointed to take medical decisions on behalf of another). There are many incapacitated patients, such as those in intensive care units, requiring ongoing therapy which is not immediately life saving. In such cases, decisions are usually made on a "best interests" basis. Despite its good intention, the legal standing of such treatment was unclear in Scotland.

Both the Law Commission and the Law Commission of Scotland published discussion papers in the early 1990s suggesting ways to improve the protection of the incapacitated. ${ }^{45}$ From these, the Adults with Incapacity (Scotland) Bill developed and this received Royal Assent as the Adults with Incapacity (Scotland) Act 2000. ${ }^{6}$

One of the most fundamental changes resulting from the Act has been the introduction of a welfare power of attorney. A welfare attorney is a person designated by the granter to act on his behalf should he become mentally incapacitated. This effectively introduces proxy decision making. The attorney's power will cease should the person regain competency.

The part of the Act pertaining to medical treatment and research is Part 5, which came into effect on 1 July 2002. The Act confers on a doctor a general authority to treat patients who are incapable of giving their own consent. The authority to treat is triggered by a certificate of incapacity stating that the medical practitioner primarily responsible for the medical treatment of the adult is of the opinion that the adult is incapable in relation to a decision about the medical treatment in question. Where a proxy with the relevant powers has been appointed then their consent will also be required. This will not in any way affect the immediate administration of emergency treatment. Whether a certificate of incapacity is still required when consent is given by a proxy decision maker, as laid out in the code of practice, remains unclear.

The intensive care unit in our hospital is a seven bed unit in a major teaching hospital and is a tertiary referral centre for burns, upper gastrointestinal surgery, and pancreatic surgery. Before the implementation of Part 5 of the Act it was customary to provide relatives with information on the patient's condition, treatment, and prognosis as a substitute for discussion directly with patient. For major decisions, such as decision for tracheostomy, it was usual to inform the relatives and invite their assent.

In conversation with the relatives of intensive care unit patients, it was our impression that they were often under the misapprehension that they already had the power to give or withhold consent on behalf of their incapacitated relative before the implementation of the Act. A questionnaire was, therefore, designed to investigate this and people's knowledge of the changes in the law in Scotland.

\section{METHODS}

The local research ethics committee approved the project. It was assumed that the person designated as next of kin would be the person most likely to be granted welfare power of attorney or to be approached for consultation, which is one of the principles of the Act. It was also known that some patients with no relatives would designate a close friend to act as their next of kin. Therefore, the next of kin for each patient was asked if they would be willing to complete a structured questionnaire (see Appendix l at http://www. jmedethics.com/supplemental). It was emphasised both 
verbally, and in the subject information sheet, that none of their responses would affect the treatment their relative was receiving. Following receiving informed consent, one researcher read the questions to the subject and recorded their answers. Patients were not involved in this study.

\section{RESULTS}

The next of kin of 100 consecutive patients completed the questionnaire. No selection or randomisation process was used and none refused to participate. The next of kin were the patient's spouse or partner $(46 \%)$, child $(23 \%)$, sibling $(15 \%)$, or parent $(12 \%)$, and only $4 \%$ were others such as more distant relatives or friends.

Eighty eight respondents (88\%) believed that they had the right under the old law to give or withhold consent on behalf of an incompetent patient (table 1). Eighty four (84\%) were confident that they could accurately represent the views of their relative despite only 13 (13\%) having ever actually discussed preferences for life sustaining treatment. One respondent $(1 \%)$ stated that for religious reasons he could not agree with the patient's wishes and therefore would not follow them. Another stated that he knew his wife's wishes because, although having never discussed these issues, they had lived together for over 25 years.

Ten $(10 \%)$ of participants were aware of the planned changes in the law with introduction of the Adults with Incapacity (Scotland) Act. All these respondents had particular reason to be aware of the impending changes. They were, for example, a critical care nurse, a justice of the peace, a social worker, and the carer of a handicapped adult. None of the other 90 respondents, of whom only two were living outside Scotland, were aware of the planned changes to the law.

Twenty two respondents (22\%) had discussed their own preferences for life sustaining therapy. Most commonly this was with their spouse or partner (17\%).

Forty nine (49\%) had heard of advanced directives before the questionnaire. None had actually written one, although $11 \%$ had considered doing so. Following the questionnaire $65 \%$ would consider drafting an advanced directive in the future.

\section{DISCUSSION}

The law in Scotland has generally assumed that adults (those aged over 16 years) are legally capable of making personal decisions for themselves and managing their own affairs. For the purposes of the Act a person is regarded as incapacitated if incapable of acting, making decisions, communicating decisions, understanding decisions, retaining memory of decisions by reason of mental disorder, or inability to communicate because of physical disorder.
Before the Adults with Incapacity (Scotland) Act, there had, in practice, been no one who could legally act on behalf of an incapacitated patient; thus they have often been left in a legal limbo. A power of attorney had no role in health care, being only responsible for financial concerns. A tutor dative could make health care decisions but could only be appointed by application to the Court of Session. This was very rarely done, partly because of the time and expense involved.

The high percentage of respondents who believed that they already have the authority to consent on behalf of an incapacitated relative would suggest a general lack of knowledge about the previous state of the law. Relatives' false perception of their power to consent was probably reinforced by the almost routine practice of involving relatives in discussion concerning life sustaining treatment as a substitute for direct discussion with the patient. Certainly, getting the relative to sign a consent form would have given the impression to the relative that their opinion did have legal weight. It was our impression that not all doctors were entirely clear on this either.

Enabling the family to act as proxy decision makers for an incapacitated patient would, at first, appear to support the concept of patient autonomy. Several studies strongly suggest that substituted judgements may not be very accurate..$^{7-12}$ Indeed, some observers have even questioned the usefulness of proxy decisions. ${ }^{13} 14$

In a study comparing the decisions of proxy decision makers' opinions with those of chronically ill elderly patients, Seckler and colleagues used a hypothetical cardiopulmonary resuscitation scenario. ${ }^{8}$ Two sets of events were studied, one using the current state of health of the patient and another assuming the development of progressive dementia. Most patients assumed that both their proxy (87\%) and their doctor $(90 \%)$ would accurately predict their wishes. In fact, this varied between $68 \%$ and $88 \%$. Family members were just as likely to provide care that the patient would not want, as to withhold care that the patient would want in both scenarios. In this study, as in ours, few patients had ever discussed resuscitation or life sustaining treatment issues with other family members $(16 \%)$ or their doctor $(7 \%)$. There appeared to be an assumption that relatives would somehow know the desires of the patient.

Some studies suggest that surrogates are more likely to subject a loved one to therapy than withhold consent for it. This may be because relatives feel guilty about withholding treatment when the alternative is allowing the patient to die. The Study to Understand Prognoses and Preferences for Outcomes and Risks of Treatments (SUPPORT Study) found that for patients wishing to receive cardiopulmonary resuscitation, the proxy's prediction was wrong in only $16 \%$ of cases.

\begin{tabular}{lll} 
Table 1 Results of the questionnaire to next of kin of intensive care patients \\
\hline & Yes (\%) & No (\%) \\
\hline $\begin{array}{lll}\text { Do you believe that the relatives currently have the legal right to make } & 88(88) & 12(12) \\
\text { healthcare decisions on behalf of an adult patient when (s)he is unable to make } & & \\
\text { these for him/herself? } & & \\
\begin{array}{l}\text { Has the patient ever discussed his/her preferences for life-sustaining treatment } \\
\text { with you? }\end{array} & 13(13) & 87(87) \\
\begin{array}{l}\text { Do you accept his/her decisions } \\
\text { Have you heard of the Adults with Incapacity (Scotland) Act? }\end{array} & 12(12) & 1(1) \\
\text { Would you feel confident to act as a proxy for (patient name) with your present } & 84(84) & 90(90) \\
\text { knowledge of his/her wishes? } & 16(16) \\
\text { Have you ever discussed your preferences for life-sustaining treatment should } \\
\text { you become critically ill? }\end{array}$ & $22(22)$ & $78(78)$ \\
Have you heard of Advanced Directives also known as 'living wills'? & $49(49)$ & $51(51)$ \\
Have you ever considered writing a 'living will'? & $11(11)$ & $89(89)$ \\
Would you consider writing a 'living will'? & $65(65)$ & $35(35)$ \\
\hline
\end{tabular}


Conversely where the patient did not wish cardiopulmonary resuscitation $50 \%$ of proxies failed to accurately predict this. ${ }^{9}$

Several respondents in our study stated that they knew the patient's wishes despite no discussion of them. Their belief was often based on the length of time that they had known or been married to their loved one. Although this was not investigated any further in our study, Sulmasy found no correlation between the time spent together and the accuracy with which a proxy could predict a person's wishes. ${ }^{10}$

In another study, Sulmasy demonstrated that a surrogate would generally choose for a patient what they would choose for themselves. This was usually the same as the patient's preference. ${ }^{11}$ Not surprisingly the accuracy of a substituted judgement is better when there has been explicit discussion between the patient and proxy. In Sulmasy's study of patients with terminal diagnoses $63 \%$ had spoken to someone about end of life issues, 33\% had an advance directive, and $31 \%$ a durable power of attorney for health care (analogous to the welfare power of attorney).

The success of the Act will be determined by how well the care of incapacitated adults is improved. Although knowledge of the changes in the law were poor, the implications for this in practice are more important. The role that relatives, or next of kin, play has become more central to the care of the incapacitated. It is, therefore, more important than ever that people ensure their wishes are known in advance of becoming mentally incapacitated for any reason (for sources of information see Appendix 2 at http://www.jmedethics. com/supplemental). The implication of not making their wishes known is that their values and aspirations cannot be taken into account when decisions need to be made on their behalf.

The evidence from the studies discussed above is that good communication is needed. The poor correlation between the subjects' desires and the predictions made by the proxies reinforce this.

\section{CONCLUSION}

The law pertaining to the care of incapacitated adults has changed in Scotland. These changes are going to have widespread effects on how the incapacitated are cared for. From this study it would appear that there is a lack of public awareness about these changes and their implications. Such information is hard to obtain and there is a general lack of study in this area. More public education is required and people should be encouraged to discuss and record their preferences for life sustaining therapy with their relatives in advance of becoming ill. One way of doing this might be by encouraging people to appoint a welfare power of attorney as this requires the granter and the potential welfare attorney to discuss the granter's wishes. An alternative approach might be to encourage the more widespread use of advanced directives, especially for known disease processes such as dementia.

The effectiveness of the Act at improving the care of the mentally incapacitated adult will depend largely on how successful it is at encouraging communication and decision making in advance of incapacity occurring.

\section{ACKNOWLEDGEMENT}

The Intensive Care Unit, Glasgow Royal Infirmary, UK also contributed to this article.

\footnotetext{
Authors' affiliations

M G Booth, P Doherty, R Fairgrieve, Department of Anaesthesia,

Glasgow Royal Infirmary, Glasgow, UK

J Kinsella, Department of Anaesthesia, Glasgow University, Glasgow, UK
}

\section{REFERENCES}

1 F v West Berkshire Health Authority [1989] 2 All England Reports 545

2 Mason JK, McCall Smith RA. Law and Medical Ethics. (5th ed) Edinburgh: Butterworths, 1999:246-248.

3 Re T (adult: refusal of medical treatment)[1992] 4 All England Reports 649 at 653.

4 Law Commission. Mental Incapacity (Law Com No 231), London: HMSO 1995.

5 Scottish Law Commission, Report on Incapable Adults, Edinburgh 1995.

6 Adults with Incapacity (Scotland) Act 2000, Edinburgh: HMSO 2000.

7 Tomlinson T, Howe K, Notman M, et al. An empirical study of proxy consent for elderly persons. Gerontologist 1990;30:54-64.

8 Seckler $\mathbf{A B}$, Meier DE, Mulvihill M, et al. Substituted judgment: how accurate are proxy predictions? Ann Intern Med 1991;115:92-8.

9 Layde PM, Beam CA, Broste SK, et al. Surrogates' predictions of seriously ill patients' resuscitation preferences. Arch Fam Med 1995:4:518-23.

10 Sulmasy DP, Haller K, Terry PB. More talk, less paper predicting the accuracy of substituted judgments. Am J Med 1994;96:432-8.

11 Sulmasy DP, Terry PB, Weisman CS, et al. The accuracy of substituted judgments in patients with terminal diagnoses. Ann Intern Med 1998; 128:621-9.

12 Mattimore TJ, Wenger NS, Desbiens NA, et al. Surrogate and physician understanding of patietns' preferences for living permanently in a nursing home. J Am Geriatr Soc 1997; 45:818-24.

13 Suhl J, Simons P, Reedy T, et al. Myth of substituted judgment. Surrogate decision making regarding life support is unreliable. Arch Intern Med 1994; 154:90-6.

14 Baergen R. Revisiting the substituted judgment standard. J Clin Ethics 1995;6:30-8.

\section{COMMENTARY}

A worrying anomaly arose in English law some forty years ago which has never been remedied, namely, that no onenot even a court of law-can consent or refuse on behalf of an incompetent adult. The response of the English courts has been to turn to the practice of "declaring" the lawfulness (or otherwise) of particular courses of conduct—such as medical interventions or withdrawals of treatment-relating to such individuals. This has been, however, a heavy burden for the judicial system to bear, especially since the decision making authority of the medical profession has come under increased scrutiny in recent years. Scotland, for its part, was unaffected by such matters. Instead, it was challenged by an anachronistic system which permitted the court appointment of proxy decision makers, but this was cumbersome and rarely used. The Adults with Incapacity (Scotland) Act 2000 did away with this system to institute a contemporary model of proxy decision making, which places primary authority squarely with the medical profession. This can only be usurped by the specific appointment of a decisional guardian, such as a relative, but even then the rights of such a person are restricted. There is-for example no "right to refuse" on behalf of the patient. Where there are disputes the further appointment of a medical arbiter must be sought and continued disagreement will be resolved by the courts. Interestingly, the Scottish legislation has rejected the use of the best interests test as a measure of legitimate interventions on incapacitated patients. This test remains the legal standard in England and Wales. It is to be contrasted with the substituted judgment test, whereby a proxy is charged with the task of taking the decision that the incapacitated person would have taken were s/he able to do so. Despite being widely used in the United States, this test has never gained legal authority in either England and Wales or Scotland. There is, however, now more scope in Scotland to consider previous declarations by an incapacitated adult as to their later medical treatment; indeed, there is an obligation to take such declarations into account. Although similar latitude is available in England and Wales if competent advance directives have been made, these may more easily be curtailed through the application of the essentially paternalistic best interests test. 
Most recently, on 17 June 2004, the Mental Capacity Bill 2004 was introduced to the Westminster Parliament in respect of reforms in England and Wales. This mirrors the Scottish framework in many ways but contains important differences. For example, there is now provision for persons, before becoming incapacitated, to appoint a donee with the power to take decisions about their welfare, property, or other specified matters once incapacity arises. This power, however, is still tempered by the best interests criterion, which the government claims builds on the common law, while offering more precise guidance. This includes an obligation to involve the incapacitated individual in each decision is far as is possible, and to have regard to the past and present wishes and feelings of the person. Furthermore, and unlike their Scottish counterparts, donees can give or refuse consent on behalf of the incapacitated person. This power does not extend to refusing life sustaining teatment unless the lasting power of attorney appointing the donee contains an express provision to this effect. In the absence of a nominated donee, an English or Welsh court would be able to take decisions on behalf of incapacitated person or appoint deputies to do so, constrained in each case by the parameters of the best interests test as stated in the legislation. It should be stressed, however, that this Bill is at an early stage and it has already provoked considerable controversy. Its successful passage through the legislative process is therefore far from guaranteed.

G Laurie
School of Law, University of Edinburgh;
Graeme.Laurie@ed.ac.uk 